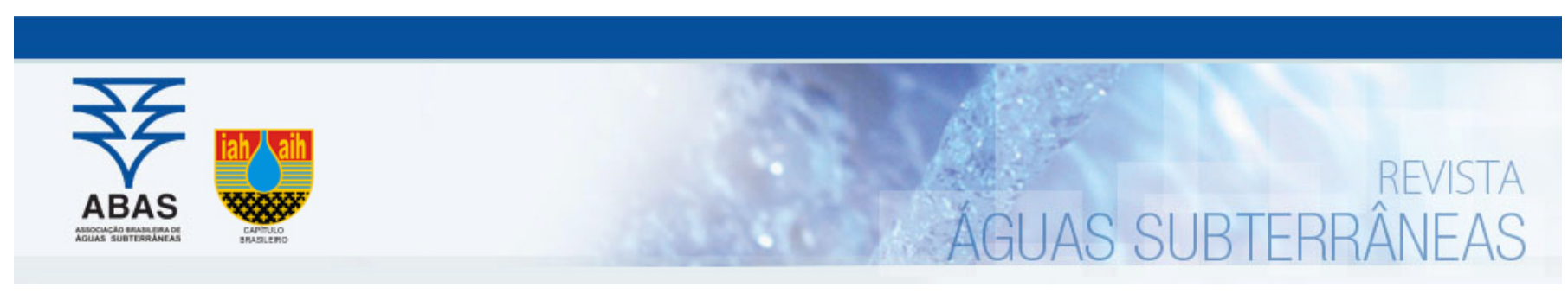

Artigos

\title{
Avaliação da influência da suinocultura na qualidade da água subterrânea - São Gabriel do Oeste - MS
}

\section{The swine breeding influence evaluation on groudwater quality - Sao Gabriel do Oeste -MS}

\section{Ana Paula Lazarin de Goehr1; Sharon Anne Nogueira Barros; Priscila Sabioni Cavalheri1; Guilherme Henrique Cavazzana1; Luiz Antônio Paiva ${ }^{1} \bowtie$}

1 Universidade Católica Dom Bosco, Campo Grande, MS

$\bowtie$ apgoehr@hotmail.com, sharon annenb@hotmail.com, priscilasabioni@hotmail.com, cavazzana.ea@gmail.com, la.paiva@terra.com.br

\begin{tabular}{|c|c|}
\hline & Resumo \\
\hline $\begin{array}{l}\text { Palavras-chave: } \\
\text { Sistema Aquífero Guarani. } \\
\text { Poços tubulares. } \\
\text { Suinocultura. } \\
\text { São Gabriel do Oeste. }\end{array}$ & $\begin{array}{l}\text { Devido à crescente demanda por água potável, os recursos subterrâneos vem assumindo um destaque significativo na gestão } \\
\text { de recursos hídricos, principalmente por serem fontes naturais mais resistentes a poluição. No entanto, em áreas rurais essa } \\
\text { contaminação pode ocorrer devido as práticas impróprias de manejo de solo e despejo inadequado dos dejetos de animais. Uma } \\
\text { das atividades agropecuárias que pode causar sérios danos ambientais é a suinocultura. Sendo assim, este trabalho objetivou } \\
\text { verificar se as atividades suinícolas instaladas no município de São Gabriel do Oeste, vêm influenciando na qualidade da água } \\
\text { subterrânea da região. Essa verificação foi possível por meio de estudos hidrogeológicos da região e pela realização das análises } \\
\text { físico-químicas e microbiológica em nove pontos de amostragem durante o período de um ano hidrológico. Com base nos levan- } \\
\text { tamentos hidrogeológicos, verificou-se que as águas explotadas nos locais amostrados são derivadas dos Aquíferos Cenozoicos, } \\
\text { Serra Geral e Guarani. Em relação as análises laboratoriais, a maioria dos parâmetros analisados não sofreram variações tem- } \\
\text { porais e mantiveram-se dentro dos limites de potabilidade estabelecido pelas legislações. Desta forma, evidenciou-se que apesar } \\
\text { da suinocultura ser uma atividade com elevado potencial poluidor, não vem interferindo na qualidade das águas subterrâneas } \\
\text { da região. }\end{array}$ \\
\hline
\end{tabular}

Abstract

Keywords:

Due to the increasing demand for drinking water, the underground resources have been assuming a significant emphasis in the management of water resources, mainly because they are natural sources more resistant to pollution. However, in rural areas this contamination may occur due to improper soil management practices and inappropriate dumping of animal waste. One of the farming activities that can cause serious environmental damage is swine farming. Thus, this work aimed to verify if the pig farming activities in the municipality of São Gabriel do Oeste, have influenced the quality of groundwater in the region. This verification was possible by means of hydrogeological studies of the region and the accomplishment of the physical-chemical and microbiological analyzes in nine sampling points during the period of one hydrological year. Based on the hydrogeological surveys, it was verified that the waters exploited in the sampled sites are derived from the Cenozoic, Serra Geral and Guarani aquifers. Regarding the laboratory analyzes, most of the analyzed parameters did not suffer temporal variations and they remained within the limits of potability established by the legislations. In this way, it was evidenced that although swine farming is an activity with high polluting potential, it does not interfere in the quality of groundwater in the region.

\section{INTRODUÇÃO}

A demanda pela água vem crescendo cada vez mais. Com as reservas superficiais cada vez mais degradadas e menos acessíveis, devido ao crescimento populacional e à expansão das atividades agrícolas e industriais, a explotação dos recursos subterrâneas tornamse uma alternativa viável para o abastecimento (ARAÚJO et al., 2016; LOBLER e SILVA, 2015).
Desta forma, a explotação das águas subterrâneas vem assumindo um destaque significativo na gestão dos recursos hídricos do Brasil, devido a sua abundância, boa qualidade e baixos custos de tratamento e distribuição. Entretanto, seu uso em larga escala, de maneira desenfreada e sem controle, coloca em risco a saúde da população e do meio ambiente, dada a vulnerabilidade natural dos aquíferos e ao gerenciamento inadequado das atividades antrópicas (UECHI, GABAS e LASTORIA, 2017). 
De acordo com Duarte et al. (2016) apesar das águas subterrâneas serem fontes naturais mais resistentes à poluição, diversos fatores podem comprometer sua qualidade. Tais fontes podem ser classificadas de acordo com sua forma de ocorrência, em pontuais e difusas. A contaminação pontual pode-se dar, através da infiltração de fossas e tanques sépticos, disposição inadequada de resíduos sólidos urbanos e industriais, postos de combustíveis (PACHECO et al., 2016; SILVA et al., 2014).

Em áreas agrícolas há a predominância de fontes de contaminação difusa, devido às práticas inadequadas de manejo do solo, relacionadas a extensas áreas de monocultura e a disposição inadequada de dejetos animais. Os casos mais graves de contaminação nessas áreas estão relacionados a presença de nitrato e metais pesados (MOURA et al., 2015; MENEZES et al., 2014; SOUZA, 2013; MARION, 2011).

Uma das atividades agropecuárias que apresenta elevado potencial poluidor devido ao volume de dejetos produzidos e ao elevado número de contaminantes contidos no efluente, é a suinocultura (SOUZA et., 2016).

Considera-se que a suinocultura brasileira, seja uma das principais atividades agropecuárias do país. Segundo o IBGE (2016a) o Brasil é o quarto maior produtor mundial e, São Gabriel do Oeste/MS é um dos 20 municípios brasileiros com maior efetivos de suínos de acordo com a Pesquisa da Pecuária Municipal do IBGE (2015).

Com o avanço tecnológico alcançado pela suinocultura brasileira, nota-se a implantação de sistemas cada vez mais confinados e produção de grandes volumes de dejetos por unidade de área (SINOTTI,
2005). Esses dejetos possuem alta concentração de matéria orgânica, nitrogênio, potássio, fósforo, patógenos e metais pesados, sendo extremamente poluentes. Entretanto, estes vêm sendo adotados como fertilizantes para o solo, porém quando aplicados em grandes quantidades podem causar sobrecarga da capacidade de filtração do solo, acúmulo de metais pesados e contaminação das águas subterrâneas (SOUZA et al., 2016; FERRARO, GABAS e LASTORIA, 2015; SINOTTI, 2005).

Neste contexto, o objetivo deste trabalho foi avaliar a qualidade das águas subterrâneas no município de São Gabriel do Oeste - MS, a fim de investigar a influência da suinocultura.

\section{2. ÁREA DE ESTUDO}

\subsection{Localização}

A área de estudo encontra-se inserida no município de São Gabriel do Oeste, localizada na região centro-norte do Estado de Mato Grosso do Sul, ocupando uma área total de $3.856 \mathrm{~km}^{2}$ e uma população de 25.443 habitantes (IBGE, 2016b).

Foram selecionados nove pontos de amostragem, sendo constituídos de oito propriedades rurais suinícolas, e um ponto localizado na área central urbana. A seleção dos pontos foi realizada com a finalidade de comparar os diferentes parâmetros analisados em diferentes locais do município, tendo como referência os valores obtidos na área urbana. Os poços analisados encontram-se localizados de acordo com a Figura 1.

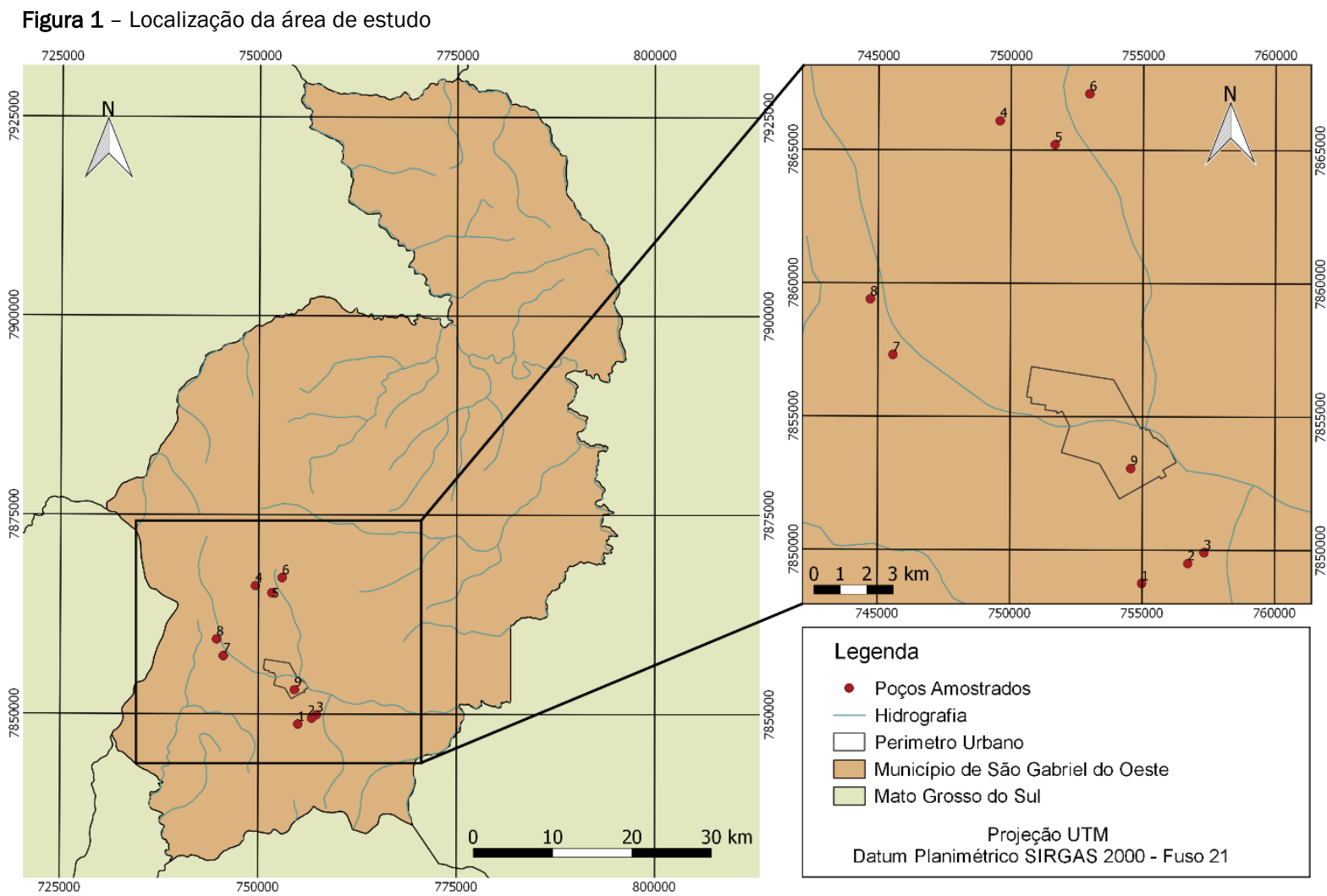




\subsection{Caracterização geológica}

Segundo Souza et al. (2014), o município situa-se sobre as Coberturas Detrito Lateríticas, que ocorrem em $48 \%$ da área superficial total, seguido pelo afloramento das formações Botucatu/Piramboia, que abrigam o Aquífero Guarani em cerca de $43 \%$ da área. De acordo com Ferraro, Gabas e Lastoria (2015), São Gabriel do Oeste encontra-se instalado sobre a zona de afloramento do Sistema Aquífero Guarani - SAG, ou como abordado por Gastmans (2007) localiza-se na terceira zona de recarga do SAG.

As Coberturas Detrito Lateríticas, que fazem parte do Sistema Aquífero Cenozóico - SAC, manifestam-se no estado de Mato Grosso do Sul, de maneira descontinua e sendo constituídos principalmente por arenitos finos com matriz síltico-argilosa com níveis subordinados de siltitos, argilitos e cascalhos a base de seixos de arenitos ferruginosos e silexitos (SOUZA et al., 2014; LACERDA FILHO et al., 2006).

De acordo com Araújo et al. (1999), o Sistema Aquífero Guarani é formado por rochas sedimentares pertencentes ao Grupo São Bento. A Formação Pirambóia é a única basal, subjacente a Formação Botucatu, com maior espessura e extensão. Sua litologia é caracterizada por um arenito esbranquiçado, as vezes com estratificação cruzada, com grãos sub-angulares e semi-arredondados, cimentação friável a compacta e intercalações síltico argilosas, formada predominantemente em ambiente continental flúvio-lacustre (LACERDA FILHO et al., 2006).

A Formação Botucatu é caracterizada por um arenito rosado friável a duro, com estratificação cruzada, granulação média-fina, bi-modal com grãos bem arredondados e esféricos, características de depó- sitos em ambiente desértico (SEPLAN, 1990).

Segundo Lastoria et al. (2006), a Formação Serra Geral é composta por uma sequência de derrames basálticos e arenitos intertrapeanos. No estado ela encontra-se assentado sobre os arenitos eólicos da Formação Botucatu, e capeada pelos arenitos continentais flúvio-lacustres do Grupo Bauru. Neste estudo, os poços amostrados captam água das Formações Aquíferas Cenozoica, Serra Geral e Guarani.

\subsection{Hidrogeologia da área de estudo}

As informações dos nove poços amostrados para o estudo foram obtidas junto a SANESUL - Empresa de Saneamento Básico de Mato Grosso do Sul, SAAE - Serviço Autônomo de Água e Esgoto de São Gabriel do Oeste, SIAGAS - Sistema de Informação de Águas Subterrâneas e IMASUL - Instituto de Meio Ambiente de Mato Grosso do Sul, conforme Tabela 1 e Figura 2.

Os locais amostrados apresentam uma litologia predominantemente composta por uma primeira camada de terra vermelha ou areia argilosa. Essa primeira camada litológica é em muitos pontos decorrente da decomposição do basalto. Sendo assim, a litologia apresentada é composta por argila, argilito, basaltos e arenitos.

De acordo com a estratigrafia, a área de estudo apresenta-se constituída por coberturas detrito lateríticas sobre uma camada de basalto assentada sobre o arenito. Relacionando a estratigrafia com a geologia local, evidencia-se que o basalto encontrado na região é derivado Formação Serra Geral, enquanto os arenitos são pertencentes à Formação Botucatu/Pirambóia.

Tabela 1 - Características dos poços amostrados no estudo

\begin{tabular}{|c|c|c|c|c|c|c|c|}
\hline Ponto & Formação Aquífera & $\begin{array}{l}\text { Longitude } \\
\left(\mathrm{g}^{\circ} \mathrm{m} \text { 's") }\right.\end{array}$ & $\begin{array}{l}\text { Latitude } \\
\left(\mathrm{g}^{\circ} \mathrm{m} \text { 's") }\right.\end{array}$ & $N E(m)$ & $\mathrm{ND}(\mathrm{m})$ & $\begin{array}{l}\text { Prof. } \\
\text { (m) }\end{array}$ & Vazão $\left(m^{3} \cdot h^{-1} \cdot m^{-1}\right)$ \\
\hline 01 & SAC, SASG, SAG & $54^{\circ} 34^{\prime} 17,6^{\prime \prime}$ & $19^{\circ} 26^{\prime} 21,6^{\prime \prime}$ & 8 & 97 & 152 & 9 \\
\hline 02 & SAC, SASG, SAG & $54^{\circ} 33^{\prime} 18,2^{\prime \prime}$ & $19^{\circ} 25^{\prime} 56,6^{\prime \prime}$ & - & - & 10 & - \\
\hline 03 & SAC, SASG, SAG & $54^{\circ} 32^{\prime} 57,5^{\prime \prime}$ & $19^{\circ} 25^{\prime} 43^{\prime \prime}$ & - & - & - & - \\
\hline 04 & SAC, SASG, SAG & $54^{\circ} 37^{\prime} 30,5^{\prime \prime}$ & $19^{\circ} 17^{\prime} 00,7^{\prime \prime}$ & 31 & 46 & 100 & 15 \\
\hline 05 & SAC, SAG & $54^{\circ} 36^{\prime} 19^{\prime \prime}$ & $19^{\circ} 17^{\prime} 28,5^{\prime \prime}$ & 24 & 54 & 105 & 15 \\
\hline 06 & SAC, SASG, SAG & $54^{\circ} 35^{\prime} 35,3^{\prime \prime}$ & $19^{\circ} 16^{\prime} 25,9^{\prime \prime}$ & 26 & 52 & 120 & 15 \\
\hline 07 & SAC, SAG & $54^{\circ} 39^{\prime} 44^{\prime \prime}$ & $19^{\circ} 21^{\prime} 47,9^{\prime \prime}$ & 15 & 32 & 151 & 28 \\
\hline 08 & SAC, SAG & $54^{\circ} 40^{\prime} 14,4^{\prime \prime}$ & $19^{\circ} 20^{\prime} 40,5^{\prime \prime}$ & 11 & 35 & 80 & 26 \\
\hline 09 & SAC, SASG, SAG & $54^{\circ} 34^{\prime} 34,2^{\prime \prime}$ & $19^{\circ} 24^{\prime} 02^{\prime \prime}$ & 10 & 18,64 & 65 & 52,8 \\
\hline
\end{tabular}

Legenda: - dados não fornecido; NE nível estático; ND nível dinâmico; Prof. profundidade.

Os poços analisados apresentam profundidades variando de 10 metros para o poço escavado manualmente (Ponto 02), enquanto os poços tubulares profundos variaram de 65 metros a 152 metros de profundidade. Baseando-se nas formações geológicas das áreas de estudo, observa-se que o Sistema Aquífero Serra Geral - SASG apresenta-se de maneira semi-confinada, enquanto o SAG encontra-se confinado ou semi-confinado de acordo com o local analisado. Nos Pontos 04, 05 e 06, o mesmo apresenta-se de maneira confinada.
Em seu estudo, Lastoria et al. (2007) já afirmava que o SAG apresenta um fluxo em meio poroso, e encontra-se em sua maior parte sob condições de confinamento, justamente sob as rochas basálticas do SASG. Enquanto o SASG se constitui de um aquífero de porosidade por fissuras e com características de um aquífero livre e/ou semi-confinado. Sendo assim, os aquíferos explotados na região de estudo são o Cenozóico, Serra Geral e Guarani. 
Figura 2 - Geologia da área de estudo

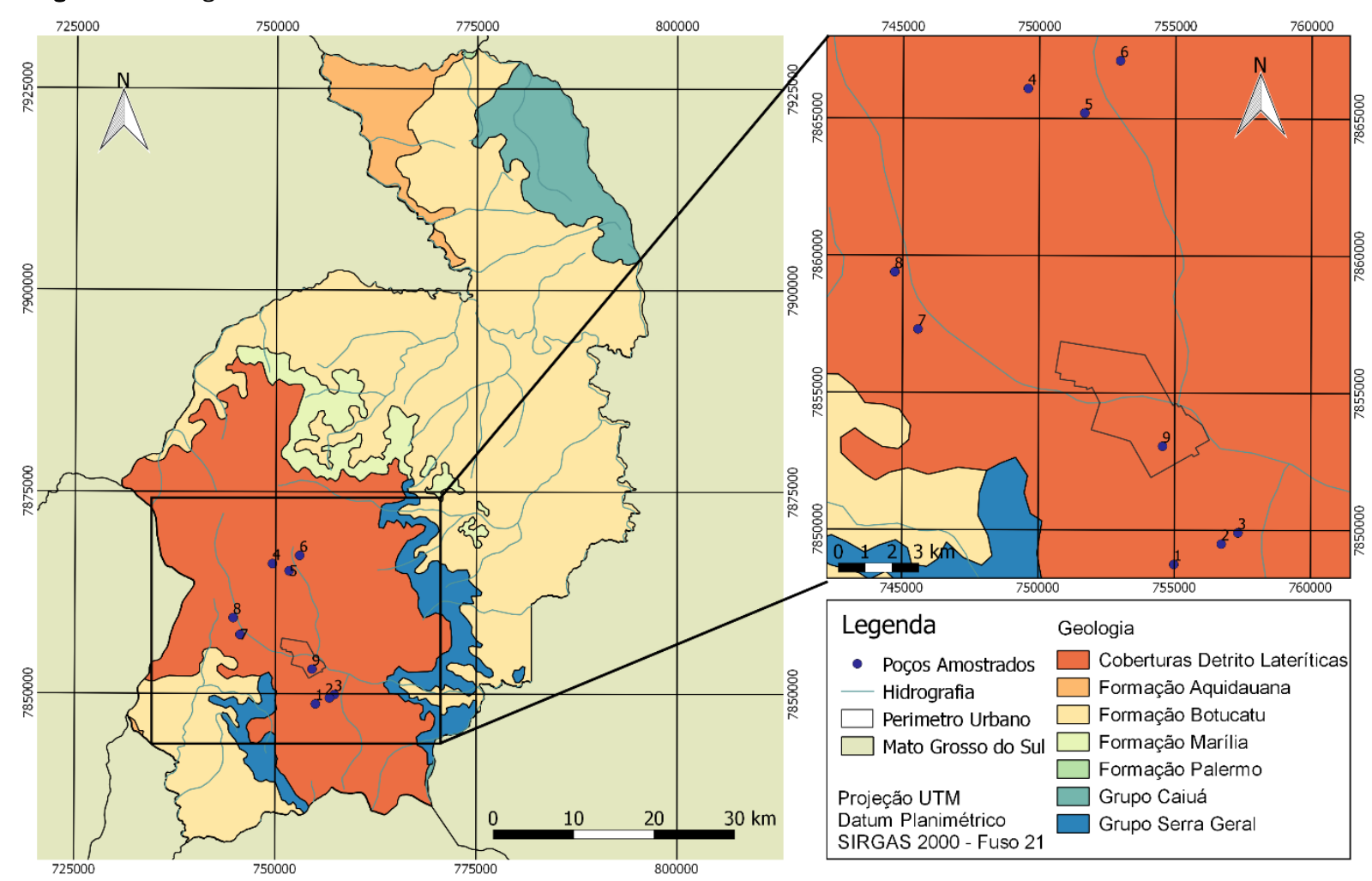

\section{ASPECTOS METODOLÓGICOS}

A amostragem foi realizada considerando o período de um ano hidrológico, sendo realizadas trimestralmente e totalizando quatro campanhas por ponto, conforme Tabela 2. A primeira foi realizada nos meses de novembro, dezembro de 2016 e janeiro de 2017 (período mais chuvoso), com temperaturas máximas variando de 33,4 a $34,3^{\circ} \mathrm{C}$, mínimas de 13,5 a $18,7^{\circ} \mathrm{C}$ e precipitações de 76,0 a $195,4 \mathrm{~mm}$. Por outro lado, a segunda campanha foi realizada nos meses de fevereiro, março e abril de 2017 (início da estiagem) com as temperaturas máximas variando de 33,2 a $33,9^{\circ} \mathrm{C}$, mínimas de 12,5 a $19,1^{\circ} \mathrm{C}$ e precipitações variando entre 23,6 a $32,6 \mathrm{~mm}$.

Tabela 2 - Caraterização das campanhas de amostragem

\begin{tabular}{|c|c|c|c|c|c|c|c|c|c|c|c|c|}
\hline \multirow[b]{2}{*}{ Mês } & \multicolumn{3}{|c|}{$1^{\circ}$ Campanha } & \multicolumn{3}{|c|}{$2^{\circ}$ Campanha } & \multicolumn{3}{|c|}{$3^{\circ}$ Campanha } & \multicolumn{3}{|c|}{$4^{\circ}$ Campanha } \\
\hline & Nov. & Dez. & Jan. & Fev. & Mar. & Abr. & Mai. & Jun. & Jul. & Ago. & Set. & Out. \\
\hline & 01 & 02 & 03 & 07 & 01 & 04 & 07 & 01 & 04 & 07 & 01 & 04 \\
\hline \multirow[t]{2}{*}{ Pontos } & 05 & 07 & 04 & 08 & 02 & 05 & 08 & 02 & 05 & 08 & 02 & 05 \\
\hline & 09 & 08 & 06 & 09 & 03 & 06 & 09 & 03 & 06 & 09 & 03 & 06 \\
\hline $\begin{array}{l}\text { Precipitação to- } \\
\text { tal (mm) }\end{array}$ & 76 & 156,4 & 195,4 & 28,6 & 23,6 & 32,6 & 46,6 & 18,6 & 0 & 85,2 & 32 & 93 \\
\hline $\begin{array}{l}\text { Temperatura } \\
\text { máxima }\left({ }^{\circ} \mathrm{C}\right)\end{array}$ & 34,3 & 33,8 & 33,4 & 33,7 & 33,9 & 33,2 & 31,1 & 30,8 & 30,8 & 35,9 & 36,4 & 37,5 \\
\hline $\begin{array}{c}\text { Temperatura mí- } \\
\text { nima }\left({ }^{\circ} \mathrm{C}\right)\end{array}$ & 13,5 & 17,6 & 18,7 & 18,5 & 19,1 & 12,5 & 16,2 & 6,8 & 2,2 & 9,8 & 14,4 & 12,9 \\
\hline
\end{tabular}

Para a coleta das amostras, utilizou-se a técnica de coleta e preservação para águas subterrâneas em conformidade com o Guia Nacional de Coleta e Preservação de Amostras da CETESB (2011). Seguindo o Guia, o plano de amostragem adotado contou com amostras simples que foram coletadas em uma única tomada de amostra.

Cada coleta foi realizada manualmente em garrafas de polietileno devidamente lavadas e esterilizadas, sendo preferivelmente coletadas imediatamente na saída dos poços, como ocorrido nos Pontos 01,08 e 09. No entanto, nos outros seis locais de amostragens, o poço não apresentava torneira para coleta, sendo necessário realizá-la na saída do reservatório.

Em campo, as amostras foram preservadas por meio da refrigeração em isopores com gelo. Após lacrado, as amostras foram encaminhadas para a realização das análises, ao Laboratório de Saneamento da Universidade Católica Dom Bosco - UCDB, localizado aproximadamente à $130 \mathrm{~km}$ dos locais de amostragem.

As análises seguiram os métodos descritos por Standard Methods for the Examination of Water and Wastewater (APHA, 2012), sendo 
analisados os seguintes parâmetros: alcalinidade, coliformes totais, condutividade total, cor, cloreto, dureza, Escherichia coli, fósforo, nitrato, nitrito, nitrogênio amoniacal, $\mathrm{pH}$, sólidos dissolvidos totais, temperatura e turbidez. Parâmetros como condutividade total, $\mathrm{pH}$, temperatura e turbidez foram medidos em campo por meio da sonda multiparâmetro da marca HANNA, modelo HI 9829.

\section{RESULTADOS E DISCUSSÕES}

Sabe-se que a qualidade da água subterrânea está diretamente associada ao uso e ocupação do solo, a natureza e composição da rocha que constitui seu aquífero, podendo dessa maneira ser afetada em maior ou menor grau por contaminantes externos.

Na Tabela 03, são apresentadas as características físico-químicas e microbiológicas das águas subterrâneas analisadas no município de São Gabriel do Oeste. Os valores foram comparados aos limites estabelecidos pela Portaria $n^{\circ} 2914 / 2011$ do Ministério da Saúde e a Resolução CONAMA nº 396/2008.

Analisando os dados da Tabela 03, com relação ao parâmetro alcalinidade, nota-se que os valores variaram de 2 a $28 \mathrm{mg} / \mathrm{L}$. Sabe-se que a alcalinidade da água subterrânea é decorrente da presença de bicarbonatos produzidos pela dissolução das rochas calcárias. Em águas naturais esse parâmetro possui valores de 30 a 500 $\mathrm{mg} / \mathrm{L}$ de $\mathrm{CaCO}_{3}$ (COELHO et al., 2017). Apesar das legislações utilizadas não fazerem referências a valores limitantes, é visto que as concentrações encontradas são relativamente baixas.

Outro parâmetro relacionado com a presença de bicarbonatos na água é a dureza. De acordo com Neto et al. (2017) a dureza total é basicamente a soma dos teores de cálcio e magnésio. Como na área de estudo há a predominância de rochas basálticas e areníticas, a presença de dureza tende a ser baixa, variando de 0,16 a $8,55 \mathrm{mg} / \mathrm{L}$, valores estes que estão de acordo com os limites estabelecidos pelas legislações vigentes CONAMA n 396/2008 e Portaria $n^{\circ} 2914 / 2011$.

Sabe-se que a elevada presença de cloreto em águas subterrâneas está relacionada com a dissolução de depósitos salinos, que são altamente móveis e não ficam retidos em rochas permeáveis (CELLIGOI, 1999). Diante os resultados encontrados neste estudo, observa-se que as pequenas concentrações de cloreto nos pontos de amostragens estão relacionados com a geologia local, uma vez que os poços são predominantemente compostos por arenito.

Os valores de condutividade elétrica estão relacionados com a salinidade da água, sendo um parâmetro utilizado para mapear o comportamento hidroquímico de um aquífero (OLIVEIRA e CAMPOS, 2011). Neste estudo os resultados encontrados variaram de 8 a 58 $\mu \mathrm{S} / \mathrm{cm}$. Souza et al. (2014) encontrou valores de $11 \mu \mathrm{S} / \mathrm{cm}$ nos poços do SAC + SAG e uma variação de 25,8 a $29,9 \mu \mathrm{S} / \mathrm{cm}$ nos locais de afloramento do SAG. A concentração de sólidos dissolvidos totais nas águas subterrâneas representam o total de minerais presentes na água. A variação nos valores encontrados foram de 12 a 92 $\mathrm{mg} / \mathrm{L}$. De acordo com os limites estabelecidos pela Portaria $\mathrm{n}^{\circ}$ 2914/2011 e CONAMA n ${ }^{\circ} 396 / 2008$, todos os pontos encontramse de acordo com os limites.

A presença de fósforo na água está relacionada a processos como a dissolução de rochas, decomposição de matéria orgânica, lançamentos de esgotos, fertilizantes e pesticidas. Em águas naturais não poluídas, as concentrações de fósforo situam-se na faixa de 0,01 a 0,05 mg/L (SILVA et al., 2014). Durante a execução deste trabalho as concentrações de fósforo foram extremamente baixas, variando de 0 a $0,045 \mathrm{mg} / \mathrm{L}$. Apesar das legislações utilizadas neste trabalho não apresentarem valores limites, observa-se que a presença de fósforo nos locais de amostragem estão de acordo com a afirmação de Silva et al. (2014).

Outros parâmetros de grande relevância, quando analisado a questão de poluição ambiental por efluentes, são nitrogênio amoniacal, nitrato e nitrito. Em ambas as análises realizadas destes parâmetros, todos os locais de amostragem apresentaram valores inferiores aos estabelecidos pela Portaria $n^{\circ}$ 2914/2011 e Resolução CONAMA n ${ }^{\circ} 396 / 2008$. Os estudos realizados por Souza et al. (2014) e Souza (2013) em São Gabriel do Oeste confirmaram os resultados inferiores ao limite máximo estabelecidos pelas legislações.

As análises de $\mathrm{pH}$ indicam o predomínio de águas ácidas, variando de 3,77 a 6,84. De modo geral, o pH das amostras coletadas em poços que explotam água dos SASG e SAG apresentaram valores de 4,80 a 6,25. Já as amostras coletadas em poços que captam apenas água do SAG tendem a ser ainda mais ácidas, variando de 4,00 a 5,80 . Entretanto, o menor valor encontrado refere-se a um poço que faz uso dos SAC, SASG e SAG.

O estudo realizado por Souza et al. (2014) no município, também apresentou valores ácidos para as águas analisadas do SAC, SASG e SAG. Diante o estabelecido pelas legislações que controlam a qualidade de água para potabilidade, a Portaria n 2914/2011, 89\% das amostras coletadas encontram-se fora do limite da faixa de 6,0 a 9,5 .

A turbidez deve-se a substâncias em suspensão ou coloidais e as medidas são feitas baseando-se na intensidade luminosa que atravessa a água (NETO et al., 2017). Sabe-se que geralmente em águas subterrâneas esse parâmetro apresenta baixos valores, devido ao efeito filtrante do solo. Neste trabalho, $8,3 \%$ das amostras encontraram-se fora do limite estabelecido pela Portaria $n^{\circ}$ 2914/2011 e CONAMA n ${ }^{\circ} 396 / 2008$. Os valores acima do estabelecido estão relacionados apenas com um ponto de amostragem (Ponto 07), sendo este associado ao elevado teor de ferro que a água captada apresenta, como apontado pelo proprietário.

Com relação aos resultados obtidos nas análises de coliformes totais, $28 \%$ das amostras avaliadas resultaram na presença de coliformes totais, o que representa 10 das 36 amostras analisadas. A presença de coliformes totais é comum em amostras de águas, solos e em material vegetal, sendo considerados indicadores ambientais e não se relacionando necessariamente com origem fecal (COELHO et al., 2017; VON SPERLING, 2014).

De acordo com os resultados obtidos, todas as análises que apresentaram a presença de coliformes totais, foram coletadas na saída das caixas d'água. Sabe-se que as condições higiênico-sanitárias e a conservação dos reservatórios de água podem ser responsáveis pela veiculação de agentes patogênicos, assumindo um importante papel na contaminação da água (CAMPOS et al., 2017). Dessa forma, não se pode confirmar se a presença de patógenos é referente a uma contaminação no aquífero explotado ou da má manutenção dos reservatórios.

Entretanto, na última campanha realizada, a coleta das amostras 
dos Pontos 03 e 05 foram realizadas na saída do poço, confirmando que os resultados positivos das análises anteriores estavam vinculadas a seus reservatórios.

Estudos realizados, como o de Motta (2012), encontraram 66,6\% de amostras contaminadas por coliformes totais, sendo $65 \%$ desse percentual amostras coletadas em torneiras ou em caixas d'água. Pacheco et al. (2016), encontrou $28,8 \%$ de contaminação em suas amostras, sendo 34 de 118 análises, e 6 pontos que apresentaram persistência da contaminação nas duas campanhas de amostragem. Apesar dos resultados, ambos autores afirmam que nem sempre a presença de coliformes totais indica a contaminação da água por bactérias patogênica ou vírus, uma vez que as águas potáveis não são totalmente isentas de microrganismos.

Confirmando essa tese, Motta (2012) afirma que a contaminação microbiológica da água não impossibilita o aproveitamento da mesma para o consumo humano, sendo apenas um indicativo da qualidade, que muitas vezes um tratamento simplificado pode deixa-la apta para o abastecimento público.

Entretanto, quando se trata da qualidade microbiológica de uma água para consumo, o parâmetro decisivo é a Escherichia Coli. Sabe-se que esta é a principal bactéria do grupo coliformes fecais, tendo como habitat primário o intestino do homem e de animais de sangue quente, sendo a única que dá garantia que a contaminação seja exclusivamente fecal (VON SPERLING, 2014; MARQUEZI et al., 2010).

Em todas as análises realizadas não foi detectada a presença da $E$. coli, o que comprova que os pontos que apresentaram contaminação por coliformes totais, não estão sendo contaminados por fezes humanas e de animais. Sendo assim, de acordo com a Portaria $n^{\circ}$ 2914/2011, em amostras individuais precedentes de poços, fontes, nascentes ou outras fontes de abastecimento sem distribuição canalizada, toleram-se a presença de coliformes totais, na ausência de E. coli (SILVA et al., 2014), sendo o caso dos Pontos 02, 03 e 05, encontrados neste estudo.

Quando comparado os valores obtidos nos poços localizados nas propriedades suinícolas, com o ponto localizado na área urbana, que serviu como parâmetro de valor para comparação, não se nota uma variação significativa. Em alguns parâmentos, como nitrogênio amoniacal, foi possível observar que a concentração encontrada no ponto da área urbana (Ponto 09) foi superior aos encontrados nas áreas de suinocultura.

Sendo assim, apesar das propriedades suinícolas de São Gabriel do Oeste/MS apresentarem um elevado potencial poluidor, e estarem instaladas em zonas de afloramento de aquíferos, elas não estão comprometendo a qualidade das águas subterrâneas da região.

Tabela 3 - Resultado das campanhas de amostragem

\begin{tabular}{|c|c|c|c|c|c|c|c|c|c|c|c|}
\hline Parâmetros & VMP & Campanhas & Ponto 01 & Ponto 02 & Ponto 03 & Ponto 04 & Ponto 05 & Ponto 06 & Ponto 07 & Ponto 08 & Ponto 09 \\
\hline \multirow{4}{*}{ Alcalinidade } & \multirow{4}{*}{ - } & $1^{\text {a }}$ Campanha & 5,00 & 6,00 & 24,00 & 6,00 & 5,00 & 10,00 & 8,00 & 6,00 & 5,00 \\
\hline & & $2^{\mathrm{a}}$ Campanha & 16,00 & 8,00 & 28,00 & 4,00 & 6,00 & 12,00 & 8,00 & 10,00 & 6,00 \\
\hline & & $3^{\mathrm{a}}$ Campanha & 18,00 & 8,00 & 20,00 & 6,00 & 2,00 & 10,00 & 8,00 & 6,00 & 10,00 \\
\hline & & $4^{a}$ Campanha & 14,00 & 6,00 & 4,00 & 8,00 & 4,00 & 10,00 & 50,00 & 12,00 & 10,00 \\
\hline \multirow{4}{*}{ Cloreto } & \multirow{4}{*}{$250 \mathrm{mg} / \mathrm{L}$} & $1^{\text {a }}$ Campanha & 5,00 & 3,00 & 2,00 & 2,50 & 5,00 & 1,50 & 2,00 & 1,00 & 5,00 \\
\hline & & $2^{\mathrm{a}}$ Campanha & 1,00 & 1,49 & 1,00 & 2,50 & 1,00 & 2,00 & 2,49 & 1,49 & 1,99 \\
\hline & & $3^{\mathrm{a}}$ Campanha & 2,00 & 1,50 & 1,00 & 2,00 & 0,50 & 1,50 & 1,00 & 3,50 & 1,00 \\
\hline & & $4^{\mathrm{a}}$ Campanha & 4,00 & 3,00 & 3,00 & 1,00 & 0,50 & 2,00 & 0,50 & 1,50 & 0,50 \\
\hline \multirow{4}{*}{ Coliformes Totais } & \multirow{4}{*}{$\begin{array}{l}\text { Ausência } \\
\text { em } 100 \text { ml }\end{array}$} & $1^{\text {a }}$ Campanha & $A$ & $\mathrm{P}$ & $\mathrm{P}$ & A & $\mathrm{P}$ & A & $A$ & A & A \\
\hline & & $2^{\mathrm{a}}$ Campanha & $A$ & $P$ & $P$ & A & $P$ & $A$ & $A$ & $A$ & $A$ \\
\hline & & $3^{\mathrm{a}}$ Campanha & A & $P$ & $\mathrm{P}$ & $A$ & $P$ & $A$ & A & A & A \\
\hline & & $4^{\mathrm{a}}$ Campanha & A & $P$ & A & A & A & $A$ & A & A & A \\
\hline \multirow{4}{*}{ Condutividade } & \multirow{4}{*}{-} & $1^{\text {a }}$ Campanha & 29,00 & 9,00 & 58,00 & 12,00 & 20,00 & 18,00 & 36,00 & 35,00 & 35,00 \\
\hline & & $2^{\mathrm{a}}$ Campanha & 31,00 & 8,00 & 51,00 & 9,00 & 18,00 & 19,00 & 36,00 & 29,00 & 39,00 \\
\hline & & $3^{a}$ Campanha & 27,00 & 9,00 & 32,00 & 13,00 & 11,00 & 22,00 & 49,00 & 25,00 & 20,00 \\
\hline & & $4^{a}$ Campanha & 29,00 & 26,00 & 8,00 & 10,00 & 9,00 & 18,00 & 54,00 & 25,00 & 31,00 \\
\hline \multirow{4}{*}{ Dureza } & \multirow{4}{*}{$500 \mathrm{mg} / \mathrm{L}$} & $1^{\text {a }}$ Campanha & 8,55 & 0,40 & 1,68 & 0,72 & 5,00 & 0,32 & 0,96 & 0,64 & 5,00 \\
\hline & & $2^{\mathrm{a}}$ Campanha & 0,52 & 1,20 & 1,00 & 0,16 & 0,24 & 0,24 & 1,12 & 0,64 & 0,64 \\
\hline & & $3^{a}$ Campanha & 0,48 & 0,80 & 1,44 & 0,56 & 0,24 & 0,32 & 0,64 & 0,48 & 0,24 \\
\hline & & $4^{a}$ Campanha & 0,64 & 0,40 & 0,24 & 0,32 & 0,80 & 0,24 & 0,64 & 0,48 & 0,16 \\
\hline \multirow{4}{*}{ E. coli } & \multirow{4}{*}{$\begin{array}{l}\text { Ausência } \\
\text { em } 100 \mathrm{ml}\end{array}$} & $1^{\text {a }}$ Campanha & $A$ & $A$ & $A$ & $A$ & $A$ & $A$ & $A$ & $A$ & $A$ \\
\hline & & $2^{\mathrm{a}}$ Campanha & A & A & $A$ & A & A & $A$ & A & A & $A$ \\
\hline & & $3^{a}$ Campanha & A & A & $A$ & A & A & $A$ & A & A & A \\
\hline & & $4^{\mathrm{a}}$ Campanha & A & $A$ & A & A & A & A & A & A & A \\
\hline \multirow{4}{*}{ Fósforo } & \multirow{4}{*}{ - } & $1^{\text {a }}$ Campanha & 0,001 & 0,037 & 0,063 & 0,000 & 0,001 & 0,030 & 0,000 & 0,010 & 0,001 \\
\hline & & $2^{\mathrm{a}}$ Campanha & 0,000 & 0,045 & 0,000 & 0,000 & 0,033 & 0,028 & 0,000 & 0,000 & 0,000 \\
\hline & & $3^{a}$ Campanha & 0,013 & 0,000 & 0,027 & 0,014 & 0,000 & 0,000 & 0,000 & 0,000 & 0,000 \\
\hline & & $4^{\mathrm{a}}$ Campanha & 0,000 & 0,000 & 0,000 & 0,000 & 0,000 & 0,000 & 0,000 & 0,000 & 0,000 \\
\hline \multirow{5}{*}{ Nitrato } & \multirow{4}{*}{$10 \mathrm{mg} / \mathrm{L}$} & $1^{\mathrm{a}}$ Campanha & 0,100 & 0,010 & 0,006 & 0,008 & 0,100 & 0,011 & 0,094 & 0,180 & 0,100 \\
\hline & & $2^{\mathrm{a}}$ Campanha & 0,006 & 0,004 & 0,006 & 0,007 & 0,004 & 0,008 & 0,067 & 0,043 & 0,048 \\
\hline & & $3^{a}$ Campanha & 0,006 & 0,003 & 0,002 & 0,006 & 0,004 & 0,004 & 0,087 & 0,025 & 0,038 \\
\hline & & $4^{\mathrm{a}}$ Campanha & 0,004 & 0,007 & 0,061 & 0,000 & 0,000 & 0,000 & 0,007 & 0,122 & 0,034 \\
\hline & \multirow{4}{*}{$1,0 \mathrm{mg} / \mathrm{L}$} & $1^{\text {a }}$ Campanha & 0,020 & 0,032 & 0,029 & 0,037 & 0,020 & 0,032 & 0,830 & 0,042 & 0,020 \\
\hline \multirow{3}{*}{ Nitrito } & & $2^{\mathrm{a}}$ Campanha & 0,004 & 0,004 & 0,007 & 0,010 & 0,004 & 0,011 & 0,019 & 0,043 & 0,000 \\
\hline & & $3^{a}$ Campanha & 0,001 & 0,004 & 0,007 & 0,008 & 0,005 & 0,010 & 0,018 & 0,005 & 0,002 \\
\hline & & $4^{a}$ Campanha & 0,000 & 0,000 & 0,001 & 0,001 & 0,001 & 0,002 & 0,008 & 0,004 & 0,003 \\
\hline \multirow{4}{*}{$\begin{array}{l}\text { Nitrogênio Amoni- } \\
\text { acal }\end{array}$} & \multirow{4}{*}{$1,5 \mathrm{mg} / \mathrm{L}$} & $1^{\mathrm{a}}$ Campanha & 0,100 & 0,000 & 0,000 & 0,022 & 0,100 & 0,068 & 0,180 & 0,180 & 0,100 \\
\hline & & $2^{\mathrm{a}}$ Campanha & 0,029 & 0,032 & 0,019 & 0,049 & 0,000 & 0,000 & 0,553 & 0,108 & 0,203 \\
\hline & & $3^{a}$ Campanha & 0,075 & 0,085 & 0,000 & 0,012 & 0,081 & 0,029 & 0,437 & 0,022 & 0,075 \\
\hline & & $4^{\mathrm{a}}$ Campanha & 0,000 & 0,000 & 0,441 & 0,016 & 0,029 & 0,022 & 0,266 & 0,029 & 0,009 \\
\hline \multirow[b]{2}{*}{$\mathrm{pH}$} & \multirow{2}{*}{6,0 a 9,5} & $1^{\text {a }}$ Campanha & 5,39 & 4,57 & 6,44 & 4,06 & 5,38 & 4,80 & 4,71 & 4,17 & 5,35 \\
\hline & & $2^{\mathrm{a}}$ Campanha & 6,25 & 6,84 & 6,69 & 4,70 & 4,53 & 5,31 & 5,19 & 4,42 & 5,48 \\
\hline
\end{tabular}


Tabela 3 - Resultado das campanhas de amostragem

\begin{tabular}{|c|c|c|c|c|c|c|c|c|c|c|c|}
\hline & & & & & & & & & & & \\
\hline Parâmetros & VMP & Campanhas & Ponto 01 & Ponto 02 & Ponto 03 & Ponto 04 & Ponto 05 & Ponto 06 & Ponto 07 & Ponto 08 & Ponto 09 \\
\hline & & $3^{\mathrm{a}}$ Campanha & 5,26 & 4,56 & 5,32 & 3,77 & 4,00 & 5,10 & 5,27 & 5,39 & 5,76 \\
\hline & & $4^{\mathrm{a}}$ Campanha & 5,18 & 5,20 & 4,90 & 4,23 & 4,56 & 4,91 & 5,80 & 4,88 & 5,21 \\
\hline & & $1^{\text {a Campanha }}$ & 45,00 & 36,00 & 80,00 & 70,00 & 47,00 & 44,00 & 84,00 & 80,00 & 29,00 \\
\hline Sólidos Dissolvi- & 1000 & $2^{\mathrm{a}}$ Campanha & 30,00 & 68,00 & 54,00 & 56,00 & 22,00 & 52,00 & 88,00 & 76,00 & 52,00 \\
\hline dos Totais & $\mathrm{mg} / \mathrm{L}$ & $3^{\mathrm{a}}$ Campanha & 88,00 & 92,00 & 34,00 & 16,00 & 18,00 & 12,00 & 34,00 & 30,00 & 84,00 \\
\hline & & $4^{\mathrm{a}}$ Campanha & 36,00 & 26,00 & 14,00 & 56,00 & 31,00 & 42,00 & 28,00 & 20,00 & 32,00 \\
\hline & & $1^{\mathrm{a}}$ Campanha & 24,00 & 24,00 & 24,00 & 25,00 & 25,00 & 25,00 & 24,00 & 25,00 & 25,00 \\
\hline & & $2^{\mathrm{a}}$ Campanha & 24,00 & 28,00 & 25,00 & 25,00 & 29,00 & 25,00 & 24,00 & 25,00 & 25,00 \\
\hline Temperatura & - & $3^{\mathrm{a}}$ Campanha & 24,00 & 24,00 & 23,00 & 31,00 & 25,00 & 25,00 & 25,00 & 26,00 & 25,00 \\
\hline & & $4^{\mathrm{a}}$ Campanha & 24,00 & 24,00 & 24,00 & 25,00 & 25,00 & 26,00 & 25,00 & 26,00 & 25,00 \\
\hline & & $1^{\mathrm{a}}$ Campanha & 0,50 & 0,00 & 0,00 & 0,00 & 0,00 & 0,00 & 18,50 & 0,00 & 0,00 \\
\hline & & $2^{\mathrm{a}}$ Campanha & 0,00 & 0,00 & 0,20 & 0,40 & 0,00 & 0,40 & 17,90 & 0,00 & 0,20 \\
\hline Iurbidez & bul & $3^{a}$ Campanha & 0,00 & 0,20 & 0,30 & 0,20 & 3,70 & 0,30 & 13,40 & 0,00 & 0,10 \\
\hline & & $4^{\mathrm{a}}$ Campanha & 0,00 & 0,00 & 0,20 & 0,00 & 0,00 & 0,00 & 6,30 & 0,20 & 0,00 \\
\hline
\end{tabular}

Legenda: $A$ = ausência; $P$ = presença; VMP = valor máximo permitido pela Portaria $n^{\circ}$ 2914/2011.

\section{CONCLUSÃO}

Evidenciou-se que o município de São Gabriel do Oeste/MS apresenta basicamente três sistemas de aquíferos produtores, o SAC, SASG e o SAG. Destes, os principais analisados na área de estudo foram o SASG e o SAG.

Foram analisadas as concentrações de alcalinidade, cloreto, coliformes totais, condutividade, dureza, E. coli, fósforo, nitrato, nitrito, nitrogênio amoniacal, $\mathrm{pH}$, sólidos dissolvidos totais, temperatura e turbidez na água subterrânea de oito poços localizados em áreas suinícolas e um poço na área urbana de São Gabriel do Oeste, referentes ao período de um ano hidrológico, novembro de 2016 a outubro de 2017.

Em geral, as concentrações de condutividade, alcalinidade, nitrogênio amoniacal, cloretos, dureza, E.coli, fósforo, nitrato, nitrito e sólidos dissolvidos totais, durante o período analisado não sofreram alterações e mantiveram-se dentro dos limites de potabilidade estabelecidos pelas legislações.

A presença de coliformes totais nos Pontos 03 e 05 durante as três primeiras campanhas estão relacionadas com a falta de manutenção dos reservatórios, sendo na última campanha de amostragem verificada sua ausência quando coletada diretamente na saída do poço.

O parâmetro turbidez, no poço 07 , apresentou valores fora dos padrões organolépticos de potabilidade, exigindo um tratamento simples para que esteja apta ao consumo humano.

Quanto ao pH encontrado, observou-se que há uma predominância de águas ácidas na área de estudo, devido à presença do solo Latossolo Vermelho-escuro. Sabe-se que esse solo encontra-se presente em toda a área de estudo, e é caracterizado pela sua elevada acidez.

Sendo assim, a qualidade das águas subterrâneas dos aquíferos analisados no município de São Gabriel do Oeste não sofrem influências das atividades suinícolas instaladas na região. Apesar de ser considerada uma atividade com elevado potencial poluidor, por meio deste trabalho, foi mostrado que a mesma não apresenta qualquer impacto sobre os aquíferos da região.

\section{AGRADECIMENTOS}

Os autores agradecem a todos os proprietários e funcionários das granjas de São Gabriel do Oeste que permitiram que esta pesquisa fosse realizada em suas propriedades. Agradecem também todas as pessoas que contribuíram para a execução deste trabalho, o pessoal do Biolaqua Ambiental, do IMASUL, da SAAE de São Gabriel do Oeste e a COOASGO.

\section{REFERÊNCIAS}

APHA (2012). Standard Methods For The Examination of Water and Wastewater. American Public Health Association, American WaterWorks Association, Water Environmental Federation, 22 ed. Washington.

ARAÚJO, L.M.; FRANÇA, A.B.; POTER, P.E. Hydrogeology of the Mercosul Aquifer System in the Paraná and Chaco-Paraná Basins, South America, and comparison with the Navajo-Nugget Aquifer System, USA. Hydrogeology Journal. 7-p. 317-336. 1999

ARAÚJO, R.S.A.; BEZERRA, A.A.; CASTRO, M.A.H. Busca pelo mínimo resíduo para escolha do parâmetro de forma utilizado em RBF's aplicadas no método assimétrico livre de malhas (Meshless) para simulação de fluxo subterrâneo. Revista Águas Subterrâneas. v.30, n.3, p.343-361, 2016.

BRASIL. CONAMA - Conselho Nacional do Meio Ambiente. Resolução $n^{\circ} 396$, de 07 de abril de 2008: Dispõe sobre a classificação e diretrizes ambientais para o enquadramento das águas subterrâneas e dá outras providencias. Brasília, 2008.

BRASIL. Ministério da Saúde. Portaria $n^{\circ}$ 2.914, de 12 de dezembro de 2011: Dispõe sobre os procedimentos de controle e vigilância da qualidade da água para consumo humano e seu padrão de potabilidade. Brasília, 2011.

CAMPOS, D.A.G.; FRANCO, J.M.; FILHO, B.A.A.; BERGAMASCO, R.; YAMAGUCHI, N.U. Avaliação da qualidade da água destinada ao consumo humano em instituição de ensino. Revista da Universidade Vale do Rio Verde. v.15, n.1, p.289-298, 2017.

CELLIGOI, A. Considerações sobre análises químicas de águas subterrâneas. Revista Geografia. v.8, n.1, p. 91-97, 1999.

CETESB; ANA. Guia nacional de coleta e preservação de amostras: água, sedimento, comunidades aquáticas e efluentes líquidos. São Paulo: CETESB; Brasília: ANA, 2011.

COELHO, S.C.; DUARTE, A.N.; AMARAL, L.S.; SANTOS, P.M.; SALLES, M.J.; SANTOS, J.A.A.; MARTINS, A.S. Monitoramento da água de poços como estratégia de avaliação sanitária em Comunidade Rural na Cidade de São Luís, MA, Brasil. Revista Ambiente e Água, v.12, n.1, p. 156-167, 2017.

DUARTE, M.L.; ZANCHI, F.B.; NEVES, J.R.D.; COSTA, H.S.; JORDÃO, W.H.C. Vulnerabilidade à contaminação das águas subterrâneas no município de Humaitá, Amazonas, Brasil. Revista Ambiente e Água, v.11, n.2, p. 402-413, 2016.

FERRARO, A.A.; GABAS, S.G.; LASTORIA, G. Origem de metais pesados em aquífero livre de São Gabriel do Oeste, Mato Grosso do Sul. Revista Geociências, v.34, n.4, p.801-815, 2015. 
GASTMANS, D. Hidrogeologia e hidroquímica do Sistema Aquífero Guaran na porção ocidental da bacia sedimentar do Paraná. Rio Claro, 2007. 238p. Tese (Doutorado em Geociências e Meio Ambiente). Instituto de Geociências e Ciências Exatas da Universidade Estadual Paulista.

IBGE. INSTITUTO BRASILEIRO DE GEOGRAFIA E ESTATÍSTICA. Indicadores IBGE: estatística da produção pecuária 2016. Rio de Janeiro, 2016a.

IBGE. INSTITUTO BRASILEIRO DE GEOGRAFIA E ESTATístICA. Produção de Pecuária Municipal: 2015. Rio de Janeiro, v. 43, p. 1-49, 2015.

IBGE. Instituto de Brasileiro de Geografia e Estatística. São Gabriel do Oeste. 2016b. Disponível em: <http://cidades.ibge.gov.br/painel/pai nel.php?lang=\&codmun=500769\&search=| | infogr\%E1ficos:-dados-geraisdo-munic\%EDpio>. Acesso em: 20 mai. 2017.

LACERDA FILHO, J.V.; BRITO, R.S.C.; SILVA, M.G.; OLIVEIRA, C.C.; MORETON L.C.; MARTINS, E.G.; LOPES, R.C.; LIMA, T.M.; LARIZZATTI, J.H.; VALETE, C.R. Geologia e recursos minerais do Estado de Mato Grosso do Sul. Goiânia: CPRM, 2004.

LASTORIA, G.; GASTMANS, D.; CHANG, H. K.; SINELI, O.; HUTCHEON, I. Evidências da conectividade hidráulica entre os sistemas aquíferos serra gera e guarani no estado de Mato Grosso Do Sul e aspectos ambientais correlacionados. In: ENCONTRO NACIONAL DE PERFURADORES DE POÇOS, 15.2007, e SIMPÓSIO DE HIDROGEOLOGIA DO SUL-SUDESTE, 1. Anais...2007.

LASTORIA, G.; SINELLI, O.; KIANG, C.H.; HUTCHEON, I.; PARANHOS FILHO, A.C.; GASTMANS, D. Hidrogeologia da Formação Serra Geral no Estado de Mato Grosso do Sul. Revista Águas Subterrâneas, v.20, n.1, p. 139-150, 2006.

LOBLER, C.A.; SILVA, J.L.S. Vulnerabilidade à contaminação das águas subterrâneas do município de Nova Palma, Rio Grande do Sul, Brasil. Revista Ambiente e Água, v.10, n.1, p. 141-152, 2015.

MARION, F.A. águas subterrâneas, atividades potencialmente contaminan tes e o aporte do geoprocessamento na definição de conflitos. Revista Geoambiente on-line, n.17, p. 31-47, 2011.

MARQUEZI, M.C.; GALLO, C.R.; DIAS, C.T.S. Comparação entre métodos para a análise de coliformes totais e E. coli em amostras de água. Revista Instituto Adolfo Lutz, v.69, n.3, p.291-296, 2010.

MENEZES, J.P.C.; BERTOSSI, A.P.A.; SANTOS, A.R.; NEVES, M.A. Correlação entre uso da terra e qualidade da água subterrânea. Revista Engenharia Sanitária e Ambiental, v.19, n.2, p. 173-186. 2014.

MOTTA, E. Caracterização e classificação das águas subterrâneas dos municípios de Ibicaré, Lacerdopólis, Ouro e Capinzal. Joaçaba, 2012. 83p. Monografia (Curso de Ciências Biológicas) - Universidade do Oeste de Santa Catarina, 2012.
MOURA, C.C.; GASTMANS, D. KIANG, C.H.; MODESTO, R.P.; RODRIGUES, P.F.; RUBY, E.C.; BORGES, A.V. Concentrações de nitrato nas águas subterrâneas em áreas rurais do município de São José do Rio Preto (SP). Revista Águas Subterrâneas, v.29, n.3, p.268-284, 2015.

NETO, W.R.N.; PEREIRA, D.C.A.; SANTOS, J.R.N.; MONTEIRO, A.S.; VILLIS, P.C.M.; MOUCHREK FILHO, V.E. Análise da potabilidade das águas dos poços rasos escavados da comunidade do Taim em São Luís - Maranhão. Revista Águas Subterrâneas, v. 31, n. 3, p. 272-280, 2017.

OLIVEIRA, L.A.; CAMPOS, J.E.G. Análise da distribuição dos parâmetros físicoquímicos das águas do Sistema Aquífero Guarani no estado de Goiás, Brasil. Revista Caminhos de Geografia, v. 12, n. 37, p. 21-30, 2011.

PACHECO, G.; COSTA, A.B.; SILVEIRA. E, O.; DEPRÁ, B.; LOBO, E.A. Calibração de um índice de qualidade de águas subterrâneas (IQNAS) para a região do Vale do Rio Pardo, RS, Brasil: nova ferramenta tecnologia para o monitoramento ambiental. Revista Águas Subterrâneas. v.30, n.3, p. 440-454, 2016

SEPLAN. SECRETARIA DE PLANEJAMENTO DE MATO GROSSO DO SUL. Atlas Multirreferencial de Mato Grosso do Sul. Coordenadoria de Recursos Naturais, Mapas, Campo Grande, 28p. 1990.

SILVA, D.D.; MIGLIORINI, R.B.; SILVA, E.C.; LIMA, Z.M.; MOURA, I.B. Falta de saneamento básico e as águas subterrâneas em aquífero freático: região do Bairro Pedra Noventa, Cuiabá (MT). Revista Engenharia Sanitária e Ambiental, v.19, n.1, p. 43-52, 2014.

SINOTTI, A.P.S. Avaliação do volume de dejetos e da carga de poluentes produzidos por suíno nas diferentes fases do ciclo criatório. Florianópolis, 2005. 85p. Dissertação (Mestrado em Agroecossistemas), Universidade Federal de Santa Catarina.

SOUZA, A.A. O aquífero cenozoico em São Gabriel do Oeste-MS. Campo Grande, 2013. 36p. Dissertação (Mestrado em Recursos Hídricos). Centro de Ciências Exatas e Tecnologia da Universidade Federal de Mato Grosso do Sul.

SOUZA, A.A.; LASTORIA, G.; GABAS, S.G.; MACHADO, C.D. Avaliação da água subterrânea nos aquíferos cenozoico e guarani em São Gabriel do Oeste-MS: subsídios à gestão integrada. Revista Ciência e Natura, v. 36 n. 2, p.169179, 2014

SOUZA, G.E.; GOSMANN, H.A.; BELLI FILHO, P.; MOHEDANO, R.A.; CASARIN, M.A.; BENEDET, L. Gestão De Recursos Naturais: Sustentabilidade. Revista MIX Sustentável, v. 2, n. 2, p.10-19, 2016.

UECHI, D.A.; GABAS, S.G.; LASTORIA, G. Análise de metais pesados no Sis tema Aquífero Bauru em Mato Grosso do Sul. Revista Engenharia Sanitária e Ambiental, v.22, n.1, p. 155-167, 2017.

VON SPERLING, M. Introdução à qualidade das águas e ao tratamento de esgoto. 4. ed. Belo Horizonte: Editora UFMG, 2014. 